\title{
Inhibition of Cyclic AMP Phosphodiesterase (PDE4) Reverses Memory Deficits Associated with NMDA Receptor Antagonism
}

\author{
Han-Ting Zhang, Ph.D., M.D., Alicia M. Crissman, B.S., Nandakumar R. Dorairaj, M.S., \\ L. Judson Chandler, Ph.D., and James M. O'Donnell, Ph.D.
}

\begin{abstract}
Rolipram, a selective inhibitor of type 4 cyclic AMP phosphodiesterase (PDE4), completely reversed the amnesic effects of $M K-801$ on working and reference memory $(F[4,64]=11.10 ; \mathrm{p}<.0001$ and $F[4,64]=2.53 ; \mathrm{p}<.05$, respectively) at doses of $0.01-0.1 \mathrm{mg} / \mathrm{kg}$ in the radial-arm maze task. Similar antagonism by rolipram of the effects of MK-801 was observed on inhibitory avoidance behavior $(F[3,35]=190.8 ; \mathrm{p}<.0001)$. In vitro evidence suggests that an increase in $C A M P$ concentrations may mediate the observed behavioral effects of rolipram. In the absence of $P D E 4$ inhibition, NMDA did not increase cAMP
\end{abstract}

concentrations in primary cultures of rat cerebral cortical neurons. However, when PDE4 was inhibited with rolipram, NMDA markedly elevated cAMP. These observations suggest that PDE4 is an integral component of the NMDA receptor-mediated signal transduction pathway involved in memory processes. Inhibitors of PDE4 may act on this pathway to produce their effects on memory and may represent a new class of cognitive enhancers.

[Neuropsychopharmacology 23:198-204, 2000] (C) 2000 American College of Neuropsychopharmacology. Published by Elsevier Science Inc. All rights reserved
KEY WORDS: Rolipram; MK-801; Cyclic AMP; Phosphodiesterase; NMDA receptor; Memory

$\mathrm{N}$-methyl-D-aspartate (NMDA) receptors are widely distributed in the brain; their density is highest in the hippocampal CA1 subregion (Monaghan and Cotman 1985; Monyeret al. 1994; Boyer et al. 1998). It has been

From the Department of Pharmacology and Therapeutics, Louisiana State University Medical Center, Shreveport, LA 71130, USA (HTZ, AMC, NRD, JMO); and Departments of Physiology/Neuroscience and Psychiatry, Center for Drug and Alcohol Programs, Medical University of South Carolina, Charleston, SC 29425, USA (LJC).

Address correspondence to: Han-Ting Zhang, Department of Pharmacology and Therapeutics, Louisiana State University Medical Center, Shreveport, LA 71130, USA, Tel.: 318-675-6632, Fax: 318675-7857, Email: hzhang@lsumc.edu

Received November 10, 1999; revised February 21, 2000; accepted February 29, 2000. shown that NMDA receptors in this area are very important in the regulation of synaptic plasticity and the process of learning and memory, especially long-term memory (Kesner and Dakis 1995; Morris et al. 1986; Nguyen and Kandel 1996; Kawabe et al. 1998). Meanwhile, NMDA elicits an increase in cAMP in the hippocampal CA1 area that is antagonized by the competitive antagonist DL-2-amino-5-phosphonovaleric acid (AP5) or removal of extracellular $\mathrm{Ca}^{2+}$ (Chetkovich et al. 1991). Antagonism of NMDA receptors not only blocks NMDA-induced increases in cAMP, but also impairs learning and memory (Morris et al. 1986; Nguyen and Kandel 1996; Kawabe et al. 1998; Chetkovich et al. 1991; Meehan 1996). These results indicate that cAMP is involved in the NMDA receptor antagonist-induced impairment of learning and memory.

Rolipram, a selective inhibitor of type 4 cAMP-specific phosphodiesterase (PDE4), produces an increase in brain cAMP levels via the inhibition of its degradation 
(Schneider 1984; Ilien et al. 1982). Behavioral studies show that rolipram inhibits locomotor activity and rearing induced by methaphetamine and produces biphasic effects on schedule-controlled behavior, increasing response rate at lower doses and decreasing response rate at higher doses (Iyo et al. 1995; O'Donnell and Frith 1999). It elicits a morphine-withdrawal-like behavioral syndrome characterized by head twitches, forepaw shaking, grooming and hypoactivity, which are related to a high level of cAMP (Wachtel 1982; Wachtel 1983). Rolipram also exhibits antidepressant-like effects in animal models and in patients with depressive disorders (O'Donnell and Frith 1999; Hebenstreit et al. 1989; O’Donnell 1993).

Recently, rolipram has been shown to reverse the impairment of either working memory or reference memory induced by the muscarinic receptor antagonist scopolamine (Egawa et al. 1997; Imanishi et al. 1997; Zhang and O'Donnell 2000). Furthermore, PDE4 has been shown to be involved in NMDA receptor-mediated signal transduction mechanisms. Chronic treatment with rolipram up-regulates NMDA receptors in the rat hippocampus (Kato et al. 1997); rolipram also attenuates the expression of the heat shock protein HSP-70 induced by the NMDA receptor antagonist MK-801 (Hashimoto et al. 1997). Thus, although there is no direct evidence linking the effect of rolipram to NMDA receptors, the results described above suggest that rolipram will reverse the amnesic effect of the NMDA receptor antagonist MK-801. Such a finding would suggest an important role for PDE4 and cAMP in signal transduction mechanisms for NMDA receptors that are involved in learning and memory.

To test the proposed hypothesis, we investigated the effects of rolipram on MK-801-induced impairment of working and reference memory in the radial-arm maze task and long-term memory in the inhibitory avoidance (passive avoidance) procedure in rats. To assess the mechanisms mediating observed behavioral effects, the interaction between the effects of rolipram and NMDA on cAMP concentrations was examined in primary cultures of rat cerebral cortical neurons.

\section{METHODS}

\section{Animals}

Male Sprague-Dawley rats (250-300 g) were housed in groups of 2-3 in plastic cages in a room that was kept at a constant temperature $\left(22^{\circ} \mathrm{C}\right)$ and on a 12-hour on / 12hour off light cycle (lights on at 0600 hours). Water and food were freely available, except for the rats used for the radial-arm maze task; for these rats, food was restricted to $16 \mathrm{~g}$ per day after test sessions, so as to maintain body weights at $80-85 \%$ of free-feeding weights.

\section{The Radial-arm Maze Test}

The test was performed as described (Zajaczkowski et al. 1996; Levin et al. 1998). In brief, five days after initial housing, rats were weighed and handled for two days before they were placed into the maze for 5 minutes in groups of 4-5 with food pellets [fruit cereal spins (Great Value, WAL-MART Inc., Bentonville, AR); each was split into three pellets. 4-5 pellets per rat] scattered randomly throughout the eight-arm radial maze (each arm was $60 \mathrm{~cm}$ long, $10 \mathrm{~cm}$ wide and $12 \mathrm{~cm}$ high; the maze was elevated $70 \mathrm{~cm}$ above the floor); this acclimation session was conducted a second day. Rats were then placed individually in the center of the maze for $5 \mathrm{~min}$ utes with food pellets placed close to the food wells and then, the next day, in the wells at the end of the arms; two sessions a day were conducted. Four randomly selected arms were then baited with one pellet of food each. The rat was restricted to the center platform (26 $\mathrm{cm}$ in diameter) for 15 seconds and then allowed to move freely throughout the maze until it collected all pellets of food or 10 minutes passed, whichever came first. Four parameters were recorded: 1) working memory errors, i.e., entries into baited arms that had already been visited during the same trial; 2) reference memory errors, i.e., entries into unbaited arms; 3 ) total arm entries; 4) the test duration (s), i.e. the time spent in the collection of all the pellets in the maze. If the working memory error was zero and the average reference memory error was less than one in five successive trials, the rats began the drug tests. Rolipram (Schering AG, Berlin, Germany) was dissolved in saline containing $10 \%$ dimethyl sulfoxide (DMSO); (+)-MK-801 hydrogen maleate (RBI, Natick, MA) was dissolved in saline alone. Rolipram was injected intraperitoneally (i.p.) 30 minutes after MK-801, which was given i.p. 60 minutes before the test. Experiments were performed in a lighted room, which contained several extra-maze visual cues.

Two types of frequencies were used to measure working and reference memory: frequency of working memory errors and frequency of reference memory errors. The frequency was calculated as the number of working or reference memory errors divided by total number of entries into the arms. The average exploration time, which was used as a measure of general locomotor activity, was calculated as the test duration divided by the total number of entries into arms.

\section{The Inhibitory Avoidance Test}

The test was performed as described (Maurice et al. 1994). The apparatus (Model E10-16SC, Coulbourn Instruments, Allentown, PA) consisted of a two-compartment chamber with an illuminated compartment connected to a darkened compartment by a guillotine door. 
The floor of the darkened compartment consisted of stainless steel rods through which an electric foot-shock could be delivered from a constant current source. All experimental groups were first habituated to the apparatus the day before the start of the experiment. During the training, the rat was placed in the illuminated compartment facing away from the closed guillotine door for one minute before the door was raised. The latency for entering the darkened compartment was recorded. After the rat entered the darkened compartment, the door was closed and a $0.5 \mathrm{~mA}$ electric shock was administered for 3 seconds. Twenty-four hours later, the rat was administered $0.1 \mathrm{mg} / \mathrm{kg}$ MK- 801 or saline, 30 minutes prior to the injection of rolipram $(0.1 \mathrm{mg} / \mathrm{kg})$ or saline, which was 30 minutes before the retention test started. The rat was again placed in the illuminated compartment, with the guillotine door open. The latency for entering the darkened compartment was recorded for up to $180 \mathrm{~s}$, at which time the trial was terminated.

\section{Preparation of Neuronal Cultures}

Cerebral cortical cultures were prepared from newborn rat pups as previously described (Chandler et al. 1997). In brief, brains were removed and placed in an isotonic salt solution containing $100 \mathrm{U}$ of penicillin G, $100 \mu \mathrm{g}$ of streptomycin and $0.25 \mu \mathrm{g}$ of amphotericin B (Fungizone) per $\mathrm{ml}$ ( $\mathrm{pH}$ 7.4). Blood vessels and pia mater were removed and the tissue chopped into approximately 2 $\mathrm{mm}$ chunks. The brain pieces were then suspended in $25 \mathrm{ml}$ of $0.25 \%$ trypsin (wt/vol) in isotonic salt solution ( $\mathrm{pH}$ 7.4) and placed in a shaking water bath for $10 \mathrm{~min}-$ utes at $37^{\circ} \mathrm{C}$ to dissociate the cells. The dissociated cell suspension was then removed and combined with 10 $\mathrm{ml}$ of DMEM containing 10\% PDHS and the undissociated chunks were mixed with $160 \mu \mathrm{g}$ of DNase 1 and triturated until the cells were dissociated. The dissociated cell suspensions were combined, centrifuged at $1000 \times \mathrm{g}$ for 10 minutes and the resulting pellet washed with $50 \mathrm{ml}$ DMEM containing 10\% PDHS. Cells were resuspended in DMEM containing 10\% PDHS and plated on poly-L-lysine coated culture dishes at a density of $4 \times 10^{6}$ cells $/ 35 \mathrm{~mm}$ dish and incubated at $37^{\circ} \mathrm{C}$ in a humidified incubator with $5 \% \mathrm{CO}_{2} / 95 \%$ air. On day 3 , cells were treated with $10 \mu \mathrm{M} \beta$-cytosine arabinoside (ARC) in DMEM containing 10\% PDHS. After two days of ARC treatment, the culture medium was replaced with DMEM containing 10\% PDHS and cultures were grown for an additional seven days before being used in experiments.

\section{Culture Treatments and cAMP Determination}

Cortical cultures were washed with $1 \mathrm{ml}$ of HEPES buffer [140 mM NaCl, $5.4 \mathrm{mM} \mathrm{KCl}, 1.8 \mathrm{mM} \mathrm{CaCl}_{2}, 100$
$\mathrm{nM}$ glycine, $15 \mathrm{mM}$ glucose and $25 \mathrm{mM}$ HEPES ( $\mathrm{pH}$ 7.4)] and incubated at $37^{\circ} \mathrm{C}$ with HEPES buffer containing $1 \mu \mathrm{M}$ TTX. After a 50-minute incubation, rolipram (1 or $10 \mu \mathrm{M}), \mathrm{MK}-801(10 \mu \mathrm{M})$ or vehicle (HEPES buffer) was added. The cultures were allowed to incubate for an additional 10 minutes followed by addition of vehicle or NMDA $(100 \mu \mathrm{M})$. After an additional 15minute incubation, the cells were scraped into $100 \mu \mathrm{l}$ of ice-cold $0.4 \mathrm{~N}$ perchloric acid, the cellular homogenate from triplicate dishes combined, probe sonicated $(\sim 5$ seconds) and centrifuged at 23,000 $\times \mathrm{g}$ for 15 minutes at $4{ }^{\circ} \mathrm{C}$. The resulting supernatant was removed and saved at $-20^{\circ} \mathrm{C}$ for subsequent determination of cAMP. The pellet was solubilized by sonication in $100 \mu \mathrm{l}$ of $1 \mathrm{~N}$ $\mathrm{NaOH}$ and protein concentration determined using the bicinchoninic acid assay (Smith et al. 1985).

\section{Data Analysis}

The data were analyzed by one-way analyses of variance (ANOVA) followed by Dunnett's multiple comparison tests except for cAMP measurement just by $t$ tests.

\section{RESULTS}

In the radial-arm maze test, MK-801 $(0.1 \mathrm{mg} / \mathrm{kg})$ significantly increased the frequency of both working and reference memory errors. Rolipram $(0.01-0.1 \mathrm{mg} / \mathrm{kg})$, in a dose-dependent fashion, decreased the frequency of both working memory errors $(\mathrm{F}[4,64]=11.10 ; p<$ $.0001)$ and reference memory errors $(\mathrm{F}[4,64]=2.53 ; p=$ $.049)$ that were increased by MK-801 (Figure 1). The minimum effective doses of rolipram were $0.05 \mathrm{mg} / \mathrm{kg}$ for working memory and $0.1 \mathrm{mg} / \mathrm{kg}$ for reference memory. At the dose used in the present study, MK-801 did not alter exploration time. However, at doses of 0.05 and $0.1 \mathrm{mg} / \mathrm{kg}$ which did not change the test duration, rolipram, in combination with MK-801, significantly decreased the total number of entries (data not shown) to such an extent that it increased the exploration time (s/entry) to $147 \%$ and $138 \%$ of saline control, respectively $(\mathrm{F}[4,64]=9.23 ; p<.0001)$ (Figure 2 ).

The effects of rolipram on memory also were investigated in the inhibitory avoidance test in rats (Figure 3 ). Naive animals took about 25 seconds to cross from the illuminated compartment to the darkened compartment of the shuttle box. Twenty-four hours following electric footshock delivery in the darkened compartment, rats pretreated with vehicle (saline + saline) did not re-enter the darkened chamber within the 180-second test period. This indicated that the rats acquired the memory regarding the aversive stimulation associated with the darkened compartment. Compared to the vehicle, pretreatment with MK-801 $(0.1 \mathrm{mg} / \mathrm{kg})$ signifi- 


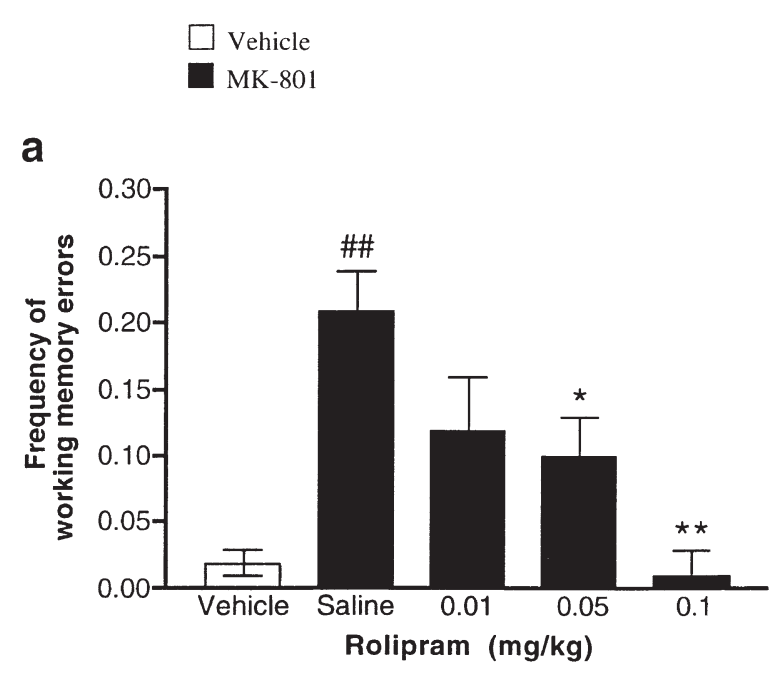

b

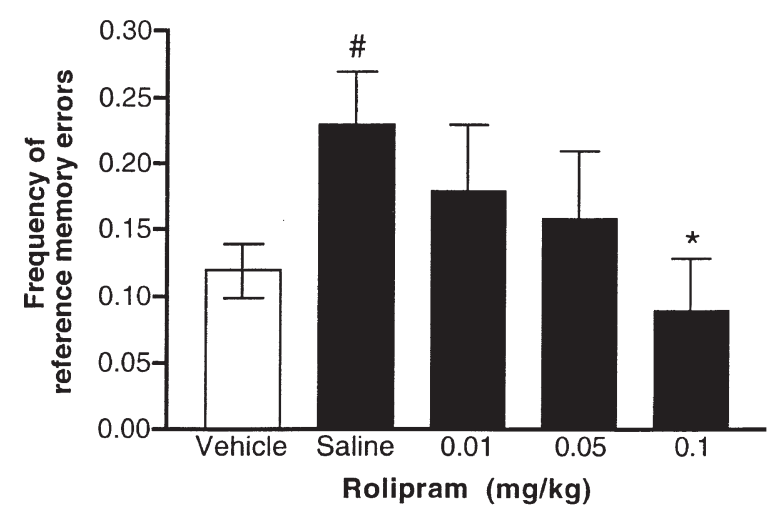

Figure 1. Effects of rolipram on MK-801-induced memory deficits in the radial-arm maze test in rats. (a) Frequency of working memory errors; (b) frequency of reference memory errors. Both rolipram and MK-801 $(0.1 \mathrm{mg} / \mathrm{kg})$ were injected i.p. Bars represent mean \pm S.E.. \# $p<.05$, \#\# $p<.01$ vs. vehicle $(\mathrm{n}=22) ;{ }^{*} p<.05,{ }^{* *} p<.01$ vs. saline (i.e., saline + MK$801 ; \mathrm{n}=18)$; for other groups, $\mathrm{n}=9-10$.

cantly reduced the latency to a value similar to that observed in naive rats. This effect of MK- 801 was completely antagonized by rolipram at a dose of 0.1 $\mathrm{mg} / \mathrm{kg}(\mathrm{F}[3,35]=190.80 ; p<.0001)$ (Figure 3$)$.

To assess the neurochemical mechanism underlying the ability of rolipram to reverse the amnesic effects of MK-801, the effects of these drugs on cAMP concentrations in primary neuronal cultures were examined. In the absence of rolipram pretreatment, NMDA $(100 \mu \mathrm{M})$ did not increase cAMP concentrations in primary cultures of rat cerebral cortical neurons (Figure 4); by contrast, under similar conditions, isoproterenol increased cAMP to more than $400 \%$ of control (data not shown). When neurons were co-incubated with 1 or $10 \mu \mathrm{M}$ rolipram, NMDA increased cAMP concentrations to $250 \%$ and $420 \%$ of control, respectively. This increase was considerably greater than that produced by either con-

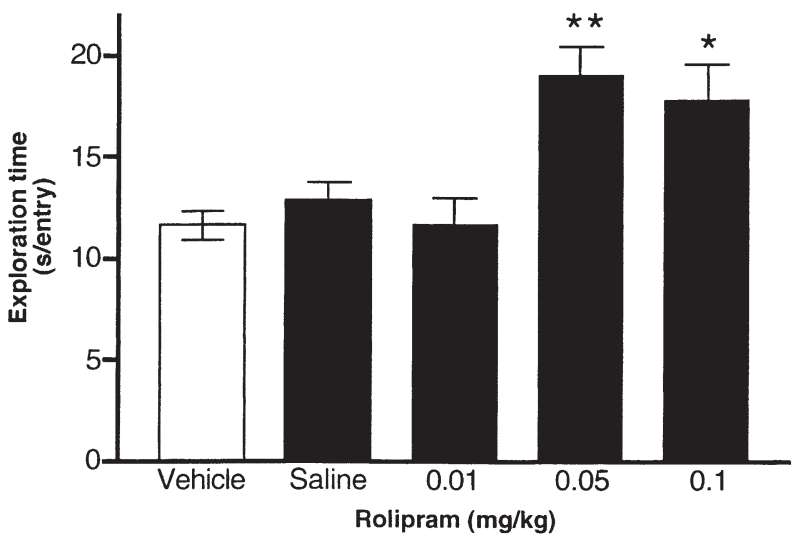

Figure 2. Effects of rolipram (i.p.) and MK-801 (0.1 mg/kg, i.p.) on the exploration time in the radial-arm maze in rats. Bars represent mean \pm S.E; ${ }^{*} p<.05,{ }^{* *} p<.01$ vs. saline $(\mathrm{n}=$ 18 ); for vehicle, $\mathrm{n}=22$; for other groups, $\mathrm{n}=9-10$.

centration of rolipram alone $(\mathrm{t}[4]=3.11 ; p<.05$ and $\mathrm{t}[4]=$ 6.57; $p<.01$ vs. corresponding value for rolipram only, respectively). The NMDA-induced increase in the cAMP concentration in the presence of rolipram was reduced to levels produced by rolipram alone when the noncompetitive NMDA antagonist MK-801 $(10 \mu \mathrm{M})$ was included in the incubation $(\mathrm{t}[4]=6.76 ; p<.01 \mathrm{vs}$. value for $10 \mu \mathrm{M}$ rolipram + NMDA) (Figure 4).

\section{DISCUSSION}

Rolipram, as well as other PDE4 inhibitors, has been shown to enhance retention in inhibitory avoidance tasks in mice at doses that elevate brain cAMP levels (Randt et al. 1982; Villiger and Dunn 1981). Recent studies show that rolipram ameliorates scopolamineinduced impairment of learning and memory in rats and mice (Egawa et al. 1997; Imanishi et al. 1997); it also improves both working and reference memory impaired by scopolamine (Zhang and O'Donnell 2000). The results of the present study show that rolipram also reverses NMDA receptor antagonist-induced impairment of memory.

In the radial-arm maze test, MK-801 significantly increased the frequency of both working and reference memory errors. This result is in agreement with previous studies (Maurice et al. 1994; Pitkanen et al. 1995). The effects of MK-801 were antagonized by rolipram. Antagonism of NMDA receptors blocks either learning (acquisition) or memory (retention performance), which is task-, dose- and time-dependent (Shapiro and 


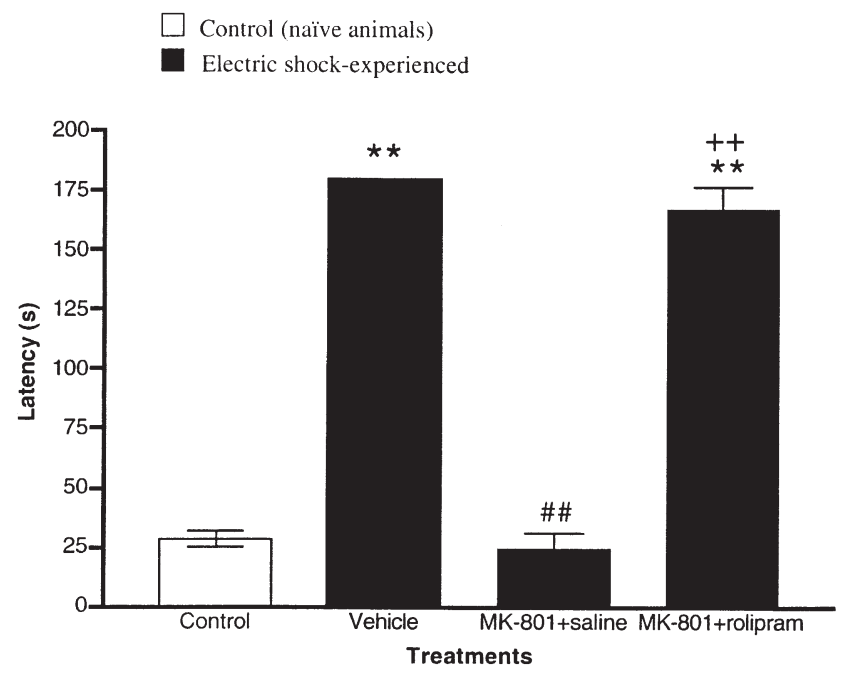

Figure 3. The effect of rolipram $(0.1 \mathrm{mg} / \mathrm{kg}$, i.p.) on MK801 ( $0.1 \mathrm{mg} / \mathrm{kg}$, i.p.) -induced memory deficits in the inhibitory avoidance test in rats. The latency was the time spent in crossing from the illuminated compartment (shock free zone) to the darkened compartment (shock zone). Bars represent mean \pm S.E.; ${ }^{* *} p<.01$ vs. control $(\mathrm{n}=20)$; \#\# $p<.01$ vs. vehicle (saline + saline, $\mathrm{n}=5$ ) $;++p<.01$ vs. MK-801 + saline $(\mathrm{n}=7)$; for MK-801 + rolipram, $\mathrm{n}=8$.

Caramanos, 1990; Mondadori and Weiskrantz, 1993; Mathis, et al. 1996; Kawabe et al. 1998). In the present task, however, since rats were well trained before drug testing and there were 3-4 days of drug-free training between two tests, which would greatly reduce the possibility of persistent amnestic effects induced by MK-801, it was working and reference memory, rather than acquisition or learning, that MK-801 impaired. Moreover, the effects of rolipram on MK-801-induced impairment of memory was not due to its role in maze performance because pretreatment with rolipram alone did not affect either working memory errors or reference memory errors (data not shown).

MK-801, at the dose used in the present study, did not alter exploration time, which provided a measure of general locomotor activity (Zajaczkowski et al. 1996). However, compared to the saline control, rolipram increased the exploration time. These effects of rolipram on the exploration time are in agreement with reports that rolipram inhibits methaphetamine-induced hyperactivity (Iyo et al. 1995) and decreases response rate of schedule-controlled behavior ( $\mathrm{O}^{\prime}$ Donnell and Frith 1999), which are not related to memory.

In the inhibitory avoidance task, 24 hours after training, rats acquired the memory related to aversive stimulation; pretreatment with MK-801 impaired retention performance, which is consistent with previous report (Mondadori and Weiskrantz, 1993). This result suggests an impairment of long-term memory induced by MK801 , which also was reversed by rolipram.

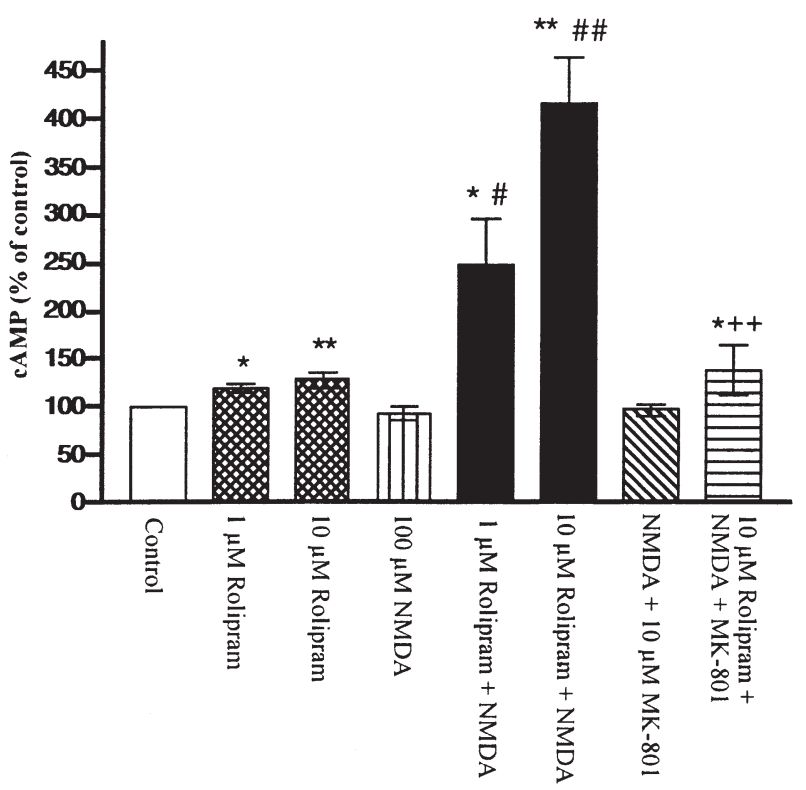

Figure 4. Effects of rolipram and NMDA $(100 \mu \mathrm{M})$ on cAMP concentrations in cultures of rat cerebral cortical neurons. Bars represent mean \pm S.E.; $\mathrm{n}=5 .{ }^{*} p<.05,{ }^{* *} p<.01$ vs. control (TTX only); \# $p<.05$, \#\# $p<.01$ vs. corresponding value for rolipram only; $++p<.01$ vs. value for $10 \mu \mathrm{M}$ rolipram + NMDA.

The present findings indicate, for the first time, that (1) rolipram enhances not only working memory but also reference memory, which are impaired by MK-801; (2) rolipram improves MK-801-induced impairment of long-term memory; (3) these effects of rolipram are likely mediated by its inhibition of PDE4.

Among these three types of memory, reference memory and long-term memory appear to be highly related to the level and function of cAMP in the brain (Barros et al. 1999; Romano et al. 1996). Considering that rolipram attenuates the MK-801-induced expression of heat shock protein HSP-70 (Hashimoto et al. 1997) and that chronic treatment with rolipram up-regulates hippocampal NMDA receptors (Kato et al. 1997), the present data suggest an interaction between PDE4 and NMDA receptors in the regulation of memory based upon the changes in cAMP levels in the brain. Such a hypothesis is also supported by the finding that NMDA increased cAMP concentrations only in the presence of rolipram; antagonism of this effect by MK801 confirmed NMDA receptor mediation (Figure 4).

Both NMDA receptors and cAMP/PKA (protein kinase A) signaling play essential roles in neuronal synaptic plasticity and memory (Morris et al. 1986; Barros et al. 1999; Frey et al. 1993; Guzowski and McGaugh 1997). Studies have shown that activation of NMDA receptors in brain regions such as the CA1 and dentate gyrus areas of the hippocampus plays an important role in the induction of long-term potentiation (LTP) 
(Morris et al. 1986; Harris et al. 1984; Collingridge et al. 1993), a form of transcription-dependent neuronal plasticity proposed as a model for the formation of longterm memory (Nguyen and Kandel 1996; Stevens 1998). NMDA also increases cAMP levels in the hippocampal CA1 area; this effect is antagonized by AP5 or removal of extracellular $\mathrm{Ca}^{2+}$ (Chetkovich et al. 1991). These results suggest that activation of NMDA receptors produces a $\mathrm{Ca}^{2+}$-dependent increase in cAMP that may play a role in the induction of LTP in the CA1 area of the hippocampus. Further studies have shown that the activation of Gs/adenylyl cyclase (AC)-coupled receptors such as beta-adrenergic and adenosine receptors are not involved in NMDA receptor-mediated increases in cAMP; these effects induced by NMDA receptor stimulation are blocked by calmodulin antagonists (Chetkovich et al. 1991; Chetkovich and Sweatt 1993). These studies support the hypothesis that NMDA receptor activation is positively coupled to AC via calcium/calmodulin (Chetkovich and Sweatt 1993). Therefore, the activation of NMDA receptors is involved in the processes of learning and memory, including both short-term and long-term memory, via its positive action in the AC/cAMP system in the brain. By blocking NMDA receptors, so as to inhibit the increase in cAMP via the mechanisms described above, MK-801 impaired both working and reference memory as well as longterm memory in the present study. These effects of MK-801 are consistent with those reported in previous studies (Pitkanen et al. 1995; White and Best 1998). Thus, rolipram attenuated the MK-801-induced impairment of memory by its inhibition of PDE4 and subsequent increase in the level of cAMP. Furthermore, although NMDA does not affect PDE4 directly (Chetkovich and Sweatt 1993), the balance between PDE4 and NMDAcoupled AC appears to play a very important role in the processing and consolidation of memory.

\section{ACKNOWLEDGMENTS}

This work was supported by research grants (MH40694, MH51175) and an Independent Scientist Award (MH01231) from the National Institute of Mental Health and a research grant from the National Institute on Alcohol Abuse and Alcoholism (AA10983). We thank Ms. Neesha Suvarna for her assistance.

\section{REFERENCES}

Barros DM, Izquierdo LA, Santa'Anna MK, Quevedo J, Medina JH, McGaugh JL, Izquierdo I (1999): Stimulators of the cAMP cascade reverse amnesia induced by intraamygdala but not intrahippocampal KN-62 administration. Neurobiol Learn Mem 71:94-103
Boyer PA, Skolnick P, Fossom LH (1998): Chronic administration of imipramine and citalopram alters the expression of NMDA receptor subunit mRNAs in mouse brain. A quantitative in situ hybridization study. J Mol Neurosci 10:219-233

Chandler LJ, Sutton G, Norwood D, Sumners C, Crews FT (1997): Chronic ethanol increases N-methyl-D-aspartate stimulated nitric oxide formation but not receptor density in cultured cortical neurons. Mol Pharmacol 51:733-740

Chetkovich DM, Gray R, Johnston D, Sweatt JD (1991): $\mathrm{N}$-methyl-D-aspartate receptor activation increases cAMP levels and voltage-gated $\mathrm{Ca} 2+$ channel activity in area CAl of hippocampus. Proc Natl Acad Sci USA 88:6467-6471

Chetkovich DM, Sweatt JD (1993): NMDA receptor activation increases cyclic AMP in area CA1 of the hippocampus via calcium/calmodulin stimulation of adenylyl cyclase. J Neurochem 61:1933-1942

Collingridge GL, Kehl SJ, McLennan H (1993): Excitatory amino acids in synaptic transmission in the Schaffercommissural pathway of the rat hippocampus. J Physiol 334:33-46

Egawa T, Mishima K, Matsumoto Y, Iwasaki K, Iwasaki K, Fujiwara M (1997): Rolipram and its optimal isomers, phosphodiesterase 4 inhibitors, attenuated the schopolamine-induced impairments of learning and memory in rats. Jpn J Pharmacol 75:275-281

Frey U, Huang YY, Kandel ER (1993): Effects of cAMP stimulate a late stage of LTP in hippocampal CA1 neurons. Science 260:1661-1664

Guzowski JF, McGaugh JL (1997): Antisense oligodeoxynucleotide-mediated disruption of hippocampal cAMP response element binding protein levels impairs consolidation of memory for water maze training. Proc Natl Acad Sci USA 94:2693-2698

Harris EW, Gonang AH, Cotman CW (1984): Long-term potentiation in the hippocampus involves activation of N-methyl-D-aspartate receptors. Brain Res 323:132137

Hashimoto K, Mishima K, Matsumoto Y, Iwasaki K, Iwasaki K, Fujiwara M (1997): Rolipram, a selective phosphodiesterase type-IV inhibitor, prevents induction of heat shock protein HSP-70 and hsp-70 mRNA in rat retrosplenial cortex by the NMDA receptor antagonist MK801. Eur J Neurosci 9:1891-1901

Hebenstreit GF, Fellerer K, Fichte K, Fischer G, Geyer N, Meya U, Sastre-y-Hernandez M, Schony W, Schratzer M, Soukop W, Trampitsch E, Varosanec S, Zawada E, Zochling R (1989): Rolipram in major depressive disorder: results of a double-blind comparative study with imipramine. Pharmacopsychiatry 22:156-160

Ilien B, Ruckstuhl M, Landry Y (1982): Pharmacological inhibition of calmodulin-sensitive phosphodiesterases. J Pharmacol 13:307-316

Imanishi T, Sawa A, Ichimaru Y, Miyashiro M, Kato S, Yamamoto T, Ueki S (1997): Ameliorating effects of rolipram on experimentally induced impairments of learning and memory in rodents. Eur J Pharmacol 321:273-278

Iyo M, Maeda Y, Inada T, Kitao Y, Sasaki H, Fukui S (1995): 
The effects of a selective cAMP phosphodiesterase inhibitor, rolipram, on methamphetamine-induced behavior. Neuropsychopharmacology 13:33-39

Kato H, Araki T, Chen T, Liu XH, Hiranuma T, Murase K, Itoyama Y, Kogure K (1997): Effects of chronic treatment with a cyclic AMP-selective phosphodiesterase inhibitor, rolipram, on excitatory amino acid neurotransmission systems in young and aged rat brains. J Neural Transm. (Budapest) 104:269-280

Kawabe K, Ichitani Y, Iwasaki T (1998): Effect of intrahippocampal AP5 treatment on radial-arm maze performance in rats. Brain Res 781:300-306

Kesner RP, Dakis M (1995): Phencyclidine injection into the dorsal hippocampus disrupt long- but not short-term memory within a spatial learning task. Psychopharmacology 120:203-208

Levin ED, Bettegowda C, Weaver T, Christopher NC (1998): Nicotine-MK-801 interactions and working and reference memory performance of rats in the radial-arm maze. Pharmacol Biochem Behav 61:335-340

Mathis C, Vogel E, Cagniard B, Criscuolo F, Ungerer A (1996): The neurosteroid pregnenolone sulfate blocks deficits induced by a competetive NMDA antagonist in active avoidance and lever-press learning tasks in mice. Neuropharmacology 35:1057-1064

Maurice T, Hiramatsu M, Itoh J, Kameyama T, Hasegawa T, Nabeshima T (1994): Behavioral evidence for a modulating role of $\sigma$ ligands in memory processes. I. Attenuation of dizocilpine (MK801)-induced amnesia. Brain Res 647:44-56

Meehan EF (1996): Effects of MK-801 on spatial memory in homing and nonhoming pigeon breeds. Behav Neurosci 110:1487-1491

Monaghan DT, Cotman CW (1985): Distribution of N-methylD-aspartate-sensitive L-[3H]-glutamate-binding sites in rat brain. J Neurosci 5:2909-2919

Mondadori C, Weiskrantz L (1993): NMDA receptor blockers facilitate and impair learning via different mechanisms. Behav Neural Biology 60:205-210

Monyer H, Burnashev N, Laurie D, Sakmann B, Seeberg P (1994): Developmental and regional expression in the rat brain and functional properties of four NMDA receptors. Neuron 12:529-540

Morris RGM, Anderson E, Lynch GS, Baudry M (1986): Selective impairment of learning and blockade of longterm potentiation by an $\mathrm{N}$-methyl-D-aspartate receptor antagonist, AP5. Nature 319:774-776

Nguyen PV, Kandel ER (1996): A macromolecular synthesisdependent late phase of long-term potentiation requiring cAMP in the medial perforant pathway of rat hippocampal slices. J Neurosci. 16:3189-3198

O'Donnell JM (1993): Antidepressant-like effects of rolipram and other inhibitors of cyclic adenosine monophosphate phosphodiesterase on behavior maintained by differential reinforcement of low response rate. J Pharmacol Exp Ther 264:1168-1178

O'Donnell JM, Frith S (1999): Behavioral effects of familyselective inhibitors of cyclic nucleotide phosphodiesterases. Pharmacol Biochem Behav 63:185-192

Pitkanen M, Sirvio J, MacDonald E, Niemi S, Ekonsalo T, Riekkinen Sr. P (1995): The effects of D-cycloserine and MK-801 on the performance of rats in two spatial learning and memory tasks. Eur Neuropsychopharmcol 5:457-463

Randt CT, Judge ME, Bonnet KA, Quartermain D (1982): Brain cyclic AMP and memory in mice. Pharmacol Biochem Behav 17:667-680

Romano A, Delorenzi A, Pedreira ME, Tomsic D, Maldonado H (1996): Acute administration of a permeant analog of cAMP and a phosphodiesterase inhibitor improve long-term habituation in the crab Chasmagnathus. Behav Brain Res 75:119-125

Schneider HH (1984): Brain cAMP response to phosphodiesterase inhibitors in rats killed by microwave irradiation or decapitation. Biochem Pharmacol 33:1690-1693

Shapiro ML, Caramanos Z (1990): NMDA antagonist MK801 impairs acquisition but not performance of spatial working and reference memory. 18:231-243

Smith PK, Krohn RI, Hermanson GT, Mallia AK, Gartner FH, Provenzano MD, Fujimoto EK, Goeke NM, Olson BJ, Klenk DC (1985): Measurement of protein using bicinchoninic acid [published erratum appears in Anal Biochem 1987 May 15; 163(1):279]. Anal Biochem 150:76-85

Stevens CF (1998): A million dollar question: Does LTP = memory? Neuron 20:1-2

Villiger JW, Dunn AJ (1981): Phosphodiesterase inhibitors facilitate memory for passive avoidance conditioning. Behav Neural Biol 31:354-359

Wachtel H (1982): Characteristic behavioral alterations in rats induced by rolipram and other selective adenosine cyclic 5-monophospho-diesterase inhibitors. Psychopharmacology 77:309-331

Wachtel H (1983): Involvement of adrenergic and opioid mechanism in the head twitches caused by the selective cAMP phosphodiesterase inhibitor rolipram in rats and guinea pigs. Naunyn Schmiedeberg's Arch Pharmacol 324: R24

White AM, Best PJ (1998): The effects of MK-801 on spatial working memory and within-session spatial learning. Pharmacol Biochem Behav 59:613-617

Zajaczkowski W, Quack G, Danysz W (1996): Infusion of (+)-MK-801 and memantine - contrasting effects on radial maze learning in rats with entohinal cortex lesion. Eur J Pharmacol 296:239-246

Zhang H-T, O'Donnell JM (2000): Effects of rolipram on scopolamine-induced impairment of working and reference memory in the radial-arm maze tests in rats. Psychopharmacology, in press 